\title{
JACOB DAVID TAMARKIN-HIS LIFE AND WORK
}

\author{
EINAR HILLE
}

Few members of our Society enjoyed such a firmly established and well deserved popularity as Jacob David Tamarkin during the twenty years that he stood in our midst. J. D., as his friends called him, was a personality and a colorful one; those who knew him well held him in fond affection and everybody respected his integrity and selfless service. The interest which he took in his fellowmen was most helpful and he stimulated mathematical activity wherever he went. His erudition and wise counsel were at the service of young and old; many of us are grateful to him for a start or a helping hand at a critical moment. He lived intensely and enjoyed it; he kept open house to his friends, and all mathematicians and musicians were his friends. He was the life of every mathematical gathering where his contagious laughter and roaring voice carried far and wide. It is a sad task to write his life; it is also a difficult one because so much of his colorful past is either hidden behind the famous curtain or cannot be told. ${ }^{1}$

J. D. was born in Chernigov (northern Ukraine; Russia) on June 28 (old style = July 11), 1888. His father was a physician, his mother belonged to the landed gentry, and he was their only child. His parents later moved to St. Petersburg where J. D. graduated from the Second Gymnasium in 1906. Among his classmates was Alexander Alexandrovich Friedmann, the future physicist. ${ }^{2}$ They were bosom friends; they worked together in school and were destined to remain closely associated until the final separation in 1925 . Their early interest went to number theory and resulted in a joint paper on quadratic congruences and the numbers of Bernoulli ([1] in the appended bibliography) which was dated October 5, 1905 and appeared in the Mathematische Annalen the following year. This was J. D.'s first paper and Friedmann became the first of his many collaborators of which at least twenty have been identified. ${ }^{3}$ The authorities of the school thought that the achievement deserved special recognition and awarded them gold medals.

${ }^{1}$ I am grateful to Professors C. R. Adams, R. C. Archibald, L. L. Silverman, S. Timoshenko, J. V. Uspensky (since deceased), and G. Vernadsky for valuable information bearing on various phases of J. D.'s life and work.

2 Born June 17, 1888, died September 16, 1925. The facts concerning Friedmann's life, used in the following, are taken from his curriculum vitae in the Receuil de Géophysique, Leningrad, vol. 5 (1927) pp. 11-15.

${ }^{3}$ See the list before the Bibliography proper. Cf. footnote 6 according to which the names of N. M. Günther and J. V. Uspensky should be added to the list. 
The two friends entered the St. Petersburg University in 1906 where they continued their work on number theory: the physicomathematical faculty also responded with gold medals. In January 1908 they wrote a letter to K. Hensel, an extract of which appeared in Crelle's Journal in 1909 [2]. This paper brought their work on number theory to a finish. They had now come under the inspiring influence of V. A. Steklov who made them interested in mathematical physics: J. D. turned to boundary value problems, Friedmann to fluid mechanics. J. D. applied the method of Steklov to a study of the transversal vibrations of an elastic homogeneous rod in [3] which appeared in 1910; his joint paper with Steklov [4] is dated the same year: It was followed by a short note [5] on the heterogeneous case in 1912, but J. D. does not seem to have carried out his intention of publishing a detailed paper. By this time he was stalking bigger game.

He graduated ${ }^{4}$ from the University in 1910 and got his first academic positions there and at the School of Communications ${ }^{5}$ the same year and, incidentally, so did Friedmann. They continued working for the Magister degree in Applied Mathematics for a few years; Friedmann passed the examination in 1913, J. D. probably in 1912. Their dissertations were delayed by the war, J. D.'s 322 page book [I] on boundary value problems appeared in 1917, Friedmann's 516 page book on hydromechanics in 1922 . In $1913 \mathrm{~J}$. D. also became instructor (privatdocent?) at the Electro-Technical School and in 1917 (extraordinary?) professor at all three institutions in Petrograd. He married Helen Weichart in 1919; their son Paul was born in 1922.

J. D.'s research during this period was concentrated on the theory of boundary value problems for linear differential equations, leading

\footnotetext{
${ }^{4}$ Professors Timoshenko and Vernadsky have furnished the following information concerning Russian university conditions before 1918 which will help the reader to get the proper perspective. The student took a four year course and received a diploma of the first or the second class upon graduation. The requirements would correspond roughly to an American M.A. degree. The best students were encouraged to stay on and became candidates for degrees of which there were two, Magister and Doctor. The requirements for the latter were so severe that very few bothered to take it. The Magister degree was hard enough; it involved an examination and the writing and public defense of a dissertation. All academic degrees were abolished in 1918. A candidate who had passed the Magister examination could obtain the venia legendi and the title of privatdocent by giving a habilitation lecture on a preassigned topic. The number of ordinary professorships (cathedrae) was small, one started out with an extraordinary position.

- Instituta Inzhenerov Pooter Soöbshcheniya. J. D. used to refer to this institute as the School of Railroads; he may have had students from the railroad section. In 1912 he was appointed member of a Russian Government committee to study stresses in rails.
} 
up to his dissertation. Later he became interested in questions of approximation (methods of W. Ritz and of C. Störmer, interpolation and mechanical quadratures) possibly through N. Krylov with whom he wrote three papers.

The very bad eyesight of J. D. presumably kept him out of the first world war. Friedmann on the other hand, who had written about airplane theory in 1911 and also had studied dynamical meteorology, saw active service with the Russian Air Force in 1914-1915 and later had a hand in research connected with aerial warfare. In 1918 Friedmann was called to the new university of Perm as professor of mechanics where he stayed for two years. J. D. accepted a call to Perm in 1920 and also stayed for two years as professor and dean. At this time starvation was widespread in Russia; living in Perm was easier than in Petrograd, but the climate was severe and J. D. nearly succumbed to an attack of pneumonia.

In 1922 we find J. D. back in Petrograd; to his three old professorships he has now added a fourth one at the Naval Academy. He also held consultantships with the Central Weather Bureau, the Optical and the Physico-Technical Institutes. The salaries were probably a minor consideration, but with each position went a set of ration cards which counted heavily in the household economy. The drawback of the many positions was that he had to spend his time on overcrowded trolley cars going from one institution to another all day long. During the three years that he remained in Petrograd, later called Leningrad, he produced an enormous amount of work. Comparatively little was pure mathematics, though the papers $[14-16,20,21]$ were written during this time, $[14]$ in collaboration with A. Besicovich and [15, 16] with Krylov. More effort must have gone into applied mathematics in collaboration with Friedmann [17-19] and still more into the three books [II, III, IV] with the co-authors J. S. Besicovich, G. Fichtenholz, A. Friedmann, and V. Smirnov. ${ }^{6}$

J. D. had been very well-to-do before the revolution razed all values. That his mathematical library was first rate, is not surprising,

' According to the Jahrbuch über die Fortschritte der Mathematik vol. 50 (1924) p. 149, the department of mathematics of the School of Communications published a collection of problems in higher mathematics to be used in the school. The authors are listed as A. A. Friedmann, N. M. Günther, J. D. Tamarkin, and J. V. Uspensky. This would add two more names to J. D.'s list of collaborators. J. D. apparently did not get much credit for his books. [II] has been issued in several editions; Smirnov added two more volumes to the book and J. D.'s name was omitted in the later editions. Neither [III] nor [IV] appeared with his name on the title page. According to J. D., [III] was awarded a prize by the Russian State Research Council and he got his share of the prize. 
but he was also intensely fond of music and he possessed a musical library of some 6000 items including a complete collection of Russian music. He used to engage a string quartet to play at his home weekly; the concert lasted from eight in the evening until five or six in the morning with an intermission for a grand supper at midnight and a good breakfast in the morning. Shostakovich, at the age of sixteen, played part of his first symphony at one of these concerts in 1924. Life was precarious, however, and for a person with J. D.'s background Leningrad was becoming unhealthy: there was always the haunting fear of starvation-he lost ninety pounds during the revolution-and there was also the secret police. J. D. was a menshevik (social democrat) and as such he was fair game both to the okhrana of the czar and the cheka after the October revolution. In 1924 he decided to leave Russia; he arrived in this country in March 1925 and was joined by his wife and son a year later. One of J. D.'s best stories told how he tried to convince the American consul in Riga of his identity: the consul attempted to examine him in analytic geometry, but ran out of questions and gave up when J. D. threatened to take over the examination.

J. D. found asylum at Dartmouth College when he came over and stayed there for two years as visiting lecturer. He used these two years well as may be seen from the Bibliography [22-32]. It is still, in the main, boundary value problems and integral equations which interested him and in these fields he found new collaborators in Ch. E. Wilder and R. E. Langer who also urged him to write an English version of his dissertation [25]. His association with L. L. Silverman resulted in a paper [32] on Abel's theorem for Nörlund and Hausdorff means which was the point of departure of much of his later work.

He was called to Brown University in 1927 and here his scientific activities really flourished. His first seven years at Brown were probably the happiest in his life. He had security and his pent-up energies overflowed in all directions. He threw himself wholeheartedly into his new surroundings where he soon became a driving force; as Brown was pushed into the mathematical front rank, good students were attracted and were well trained (J. D. alone accounted for some twenty-two Ph.D.'s during his eighteen years of active service). His stimulating lectures were highly polished and represented up-to-date research in the field in question; mimeographed copies of his lecture notes were widely circulated and quoted. He read passionately and his students as well as his friends profited much from his constructive criticism.

His critical ability and great erudition were soon put to use. $\mathrm{He}$ 
became an associate editor of the Transactions in 1927, of the Annals in 1928, and of the Zentralblatt in 1932. He became one of the editors of the Transactions in 1932, but transferred to the Colloquium Committee in 1937. He was one of the editors of the Mathematical Reviews when it started in 1940 and of the Mathematical Surveys in 1945. J. D. was also one of the moving forces of the Organizing Committee for the International Congress which was to have been held in 1940. He was an influential and much trusted member of the Council of the Society since 1931 and Vice President in 1942-1943.

J. D. wrote his first letter to me in June 1925 ; we met in person at the Cornell meeting of the same year and remained in steady contact for the rest of his life. Our active collaboration started in the late fall of 1927, the first research project being the frequency of the characteristic values of an analytical kernel. This program was soon expanded to more general problems in the theory of linear integral equations, but our ambitious plans of writing the book in the field never materialized. In April 1928 we added Nörlund summability of Fourier series and in May Hausdorff summability. The latter also included questions of relative inclusion and turned out to be particularly fruitful since it led us into the theory of Fourier transforms and Laplace-Stieltjes integrals. A number of results never got beyond the stage of preliminary communications, however. A memoir on R. Schmidt summability which should have concluded the applications to Fourier series was put off indefinitely. Likewise planned memoirs on Hausdorff summability and on Laplace-Stieltjes integrals were postponed for various reasons. During the seven years that we worked together constantly we produced 24 notes and papers; to this should be added a paper with A. C. Offord [66] and one with G. Szegö [69]. Though J. D. devoted most of his energies to our joint work during this period, he wrote six short but good papers of his own and also found time to collaborate with H. L. Krall, S. Saks, and M. H. Stone. This was the time when the new functional analysis broke through in this country and J. D. in his writings and, perhaps still more, in his teaching became a strong and influential protagonist of the new ideas.

The happiness of J. D. came to an end in June 1934 with the sudden death of his wife and from this blow he never recovered. The effect on his scientific life was immediate and destructive. He published only four papers after 1935, but a great effort still went into his lecture notes and some of his best students belong to this later period. After the outbreak of the war, most of his energy was consumed by the course in partial differential equations $[E]$ which he and W. Feller 
gave in the School of Applied Mechanics at Brown. He found time, however, to finish an excellent book on the moment problem [V], the first volume in the Mathematical Surveys, which he wrote with his old friend and university mate J. Shohat. His other co-authors during this period, in addition to those previously mentioned, are N. Dunford and A. Zygmund.

J. D.'s constitution had a number of weak spots which gradually became more serious; in February 1945 his heart threatened to give in completely, but he recovered and took part in the April meeting of the Council in his old vigorous manner. A trip to his beloved California broke him down again and he died in Washington, D. C. on November 18,1945 . He is survived by his son.

After this sketch of J. D.'s life, I shall proceed to a brief account of his scientific production which will be grouped according to subjects. If I should be found guilty of writing more fully about the investigations in which I have participated, this is due to my having a much better understanding of the ideas involved in these papers. J. D. published 71 research papers and 3 of his books are also of research character. He wrote 36 reviews in this BuLlETIN as well as many reviews in the Zentralblatt and the Mathematical Reviews. These frequently contain original contributions and the same is true of his lecture notes.

1. Number theory $[1,2]$. These papers were mentioned above. It is enough to add that the main problem in [1] is to give an explicit solution of the congruence $x^{2} \equiv q(\bmod p)$ for the case in which $p \equiv 1$ $(\bmod 4)$.

2. Calculus; functions of real or complex variables $[9,22-24,29$, $31,39,40,47,51]$. Here [51] is an important contribution to the theory of conjugate functions in the case when $p=1$ and extends work by M. Riesz, Hardy, Kolmogoroff, and Zygmund. The basic result is an inequality for $\int_{0}^{2 \pi}\left|v\left(r e^{i \theta}\right)\right| d \theta, r<1$, where $v(z)$ is the imaginary part of a function holomorphic in the unit circle. The inequality has various important consequences and is, in a certain sense, the best of its kind. [29] is connected with [I] and [25] and is concerned with the distribution of the zeros of certain entire functions of exponential type which arise in the theory of boundary value problems. Among the papers on functions of a real variable it is enough to mention [24], which contains a new proof for the closure of the trigonometric orthogonal system, and [39], which gives simple proofs of the basic properties of Lebesgue's monotone function associated with the set of Cantor. 
3. General theory of summability $[32,56,65]$. J. D.'s lively interest in questions of summability dates from his association with Silverman. In [32] they proved that a series which is summable Hausdorff $[H, q(u)]$ is not summable Abel if the corresponding moment function $\int_{0}^{1} u^{z} d q(u)$ has a zero in the right half-plane, while every Nörlund summable series is also summable Abel. The Hausdorff $\rightarrow$ Abel problem was later solved and generalized by $\mathrm{O}$. Henrikson in Math. Zeit. vol. 39 (1935) pp. 501-510. J. D. found that Nörlund's definition of summability had been considered by G. F. Voronoi in a rare Russian publication from 1901, so he published an annotated translation of Voronoi's note in Ann. of Math. (2) vol. 33 (1932) pp. 422-428. Some questions raised by $\mathrm{J}$. D. in this connection were solved later by R. E. Gilman and G. Szegö. In [56] J. D. and I considered the question of relative inclusion of Hausdorff means; we reformulated Hausdorff's conditions in terms of moment functions and mass functions and applied the results to various special questions. Our conditions for $[H, q(u)] \supset(C, n)$ are not correctly formulated (see Garabedian, Hille, and Wall, Duke Math. J. vol. 8 (1941) pp. 193-213). The fascinating problem of the arithmetic of Hausdorff matrices and of moment functions, raised in [56], is still unsolved. In [65] J. D. showed, as a consequence of the uniform boundedness theorem, that a certain plausible extension of the notion of regularity in the theory of summability actually reduces to the classical concept.

4. Summability of Fourier series $[34-38,50,52-55]$. In [36] and later papers we introduced various notions of effectiveness of a method of summability with respect to Fourier series, conjugate series, derived series, and so on. In [34] and [50] we determined suffcient conditions for different types of effectiveness of a Nörlund method of summation; in the most important case of positive monotone decreasing weight factors the conditions are also necessary. The corresponding problem for Hausdorff means was tackled in [34-37, 55]. A necessary condition for $(F)$-effectiveness was found to be that $C(s) \in L(-\infty, \infty)$ where $C(s)$ is the cosine transform of the function which equals $q(u)-u$ in $(0,1)$ and zero elsewhere. That this condition is also sufficient is indicated in a footnote in [55], but the proof is still unpublished, and the sufficiency proof in [55] involves an additional restrictive end point condition on $q(u)$. If the latter holds and if $|C(s)|$ is dominated by a monotone function in $L(0, \infty)$, then the method is also $(L)$-effective, that is, sums the Fourier series of $f(x)$ to the $\operatorname{sum} f(x)$ in the Lebesgue set of the function. For the conjugate series the corresponding sine transform plays a similar role. 
During 1931-1933 we investigated the $(F)$-effectiveness of many methods of summation and were frequently led to a condition involving the integrability over $(-\infty, \infty)$ of the Fourier transform of a kernel associated with the method. A number of such results were announced in my symposium address on the summation of Fourier series in Bull. Amer. Math. Soc. vol. 38 (1932) pp. 505-528, but the detailed discussion which we had planned was not published when it was found that the main result of [38] was erroneous in the generality there stated.

In [54] we discussed a method of summability by convergence factors defined by a regular matrix in which each row is a factor sequence of type $\left(L_{p}, L_{p}\right)$ with respect to a given orthogonal system. If the method is $\left(L_{p}\right)$-effective, it was shown to be $\left(L_{q}\right)$-effective for $p \leqq q \leqq p^{\prime}$, and all $\left(L_{1}\right)$-effective methods were determined for trigonometric Fourier series. The main tool was the convexity theorem of M. Riesz for bilinear forms.

5. Moment problems; Fourier and Laplace transforms [V, 48, 5863, 66, 67]. There are many moment problems in the literature; they may look artificial to the outsider, but they have led to the introduction of many new fruitful ideas in analysis and they have a bearing on a great variety of problems (continued fractions, functions of positive real part, positive functionals, quasi-analytic functions, and so on). The Hausdorff means are based on a sequence of moments for the interval $[0,1]$ and lead to the Hausdorff moment problem: determine a function $q(u)$ never decreasing and bounded in $[0,1]$ or of bounded variation in $[0,1]$ such that the moments $\int_{0}^{1} u^{n} d q(u), n=0,1,2, \cdots$, have given values. [48] is a contribution to this problem; J. D. gives a new proof of the Hausdorff-Bernstein-Widder theorem according to which a function completely monotone in $[0, \infty)$ is the LaplaceStieltjes transform of a monotone bounded function. In [V] he and J. Shohat gave a survey of the theory of moment problems including history, general problems and methods, the Hamburger moment problem for $(-\infty, \infty)$, various modified problems, and the related theory of mechanical quadratures with an extensive bibliography.

The theories of Fourier and Laplace transforms are closely related to each other and to the theory of functions holomorphic in a halfplane, having boundary values in $L_{p}(-\infty, \infty)$ in terms of which the functions are representable by their proper Cauchy and Poisson integrals. One may ask when a given function $f(x)$ is such a boundary function; for $p=2$ the answer has been given by Paley and Wiener and we extended their work to the range $1 \leqq p \leqq 2$ in [58]. We solved 
a similar question in [62] where $f(x)$ is supposed to be a Fourier transform. Related questions also occur in [67], but here the main problem is to give sufficient conditions under which the Fourier transform of the boundary function belongs to $L(-\infty, \infty)$. It was remarked above that the question of when a Fourier transform belongs to $L$ is basic for the summation theory of Fourier series; a number of sufficient conditions were also proved in [55].

If $f(u) \in L_{p}, 1<p<2$, Titchmarsh proved that the Fourier transform $F(t)$ of $f(u)$ exists as a limit in the mean of order $p^{\prime}$; in [61] we proved conversely that $f(u)$ is the limit in the mean of order $p$, when $a \rightarrow \infty$, of the Fourier transform of the function which equals $F(-t)$ in $(-a, a)$ and zero outside. This is no longer true when $p=1$. The note also gave basic properties of the Dirichlet transform of $f(u)$ and served as the point of departure for later work on this transform by H. Kober and by myself. Note [66] contains the essence of a correspondence with A. C. Offord; it was observed, among other things, that for a fixed $p>2$ the elements of $L_{p}$ having a Fourier transform in any $L_{q}$ form a set of the first category in the metric space $L_{p}$.

The remaining papers under this heading deal with LaplaceStieltjes integrals and are closely connected with [56]. The initial question is when an analytic function is a moment function, that is, the Laplace-Stieltjes transform of a function of bounded variation in $[0, \infty)$. Some sufficient conditions are stated in [59], but the main result here is that every function $f(z) \in H_{p}, 1 \leqq p \leqq 2$, that is, such that $\int_{-\infty}^{\infty}|f(x+i y)|^{p} d y \leqq M$ for $x>0$, is the Laplace transform of a function $F(t)$ in $L_{p^{\prime}}(0, \infty)$ (for $p=1$ proved by Bochner, for $p=2$ by Paley-Wiener, the general case was later discussed in detail by G. Doetsch along the lines indicated by us). When $2<p$, the situation is entirely different. In this case $f(z)$ is the Laplace-Stieltjes transform of a continuous function $A(t)$ and the functions $f(z)$ for which $A(t)$ is of bounded variation in any interval form a set of the first category in the metric space $H_{p}$. In [63] we introduced a new idea in the theory of summability of Laplace integrals based upon the trivial identity $f(z)=[g(z)]^{-1} g(z) f(z)$, where the multiplier $g(z)$ is supposed to be holomorphic, different from zero, and representable by an absolutely convergent Laplace-Stieltjes integral in a given halfplane $\Re(z)>\beta$. If $f(z)$ admits of a representation by an absolutely convergent Laplace-Stieltjes integral for $\Re(z)>\sigma$, so does $g(z) f(z)$, provided $\sigma \geqq \beta$, so that the transformation by multipliers is convergence preserving. If, in particular, $g(z)=z^{-\alpha}$, then the resulting representation for $f(z)$ is equivalent to that furnished by $(C, \alpha)$-summability as long as $\Re(z)>0$. These ideas were developed somewhat further 
in my address on Laplace integrals in the Proceedings of the Eighth Scandinavian Mathematical Congress in Stockholm 1934, but detailed proofs are still missing.

6. Differential equations $[12,14,30,41]$. Here [12] contains a uniqueness theorem, [14] uses results of Besicovich to extend the asymptotic form of the solution of a linear differential system from real to complex values of a parameter, and [30] is mainly of didactic interest. Finally [41] contains a very useful estimate of the variation of the solution of a differential system with the coefficients of the system.

7. Boundary value problems; Green's function [I, 3-8, 25, 27, 43, 46]. This is the field which formed the center of J. D.'s interest during a period of almost twenty years. In [3-5] he is concerned with the problem of the transversal vibrations of a clamped rod which leads to a fourth order problem

$$
\left[r(x) V^{\prime \prime}\right]^{\prime \prime}=\lambda p(x) V, \quad V(a)=V(b)=V^{\prime}(a)=V^{\prime}(b)=0 .
$$

If the rod is homogeneous, $p(x)$ and $q(x)$ are positive constants and the problem is much simplified. J. D. proved that any twice differentiable function satisfying the boundary conditions can be represented as a uniformly convergent series in terms of characteristic functions. In these investigations he used the methods of Steklov which are restricted to self-adjoint problems.

In 1911-1912 he got the idea of attacking the boundary value problem for a general $n$th order linear differential equation by the method of Cauchy-Poincaré. This method requires a fairly accurate knowledge of the asymptotic character of the solutions for large values of the parameter as well as of the distribution of the characteristic values. J. D. proceeded to derive the required information and to apply it to the boundary value and expansion problem. During this process he found, much to his chagrin, that the problem had already been attacked by G. D. Birkhoff, using the same method, in Trans. Amer. Math. Soc. vol. 9 (1908) pp. 219-231, 373-395. He decided nevertheless to publish his results for the expansion problem in [6], replacing his own discussion of the asymptotic formulas by Birkhoff's. J. D. thought that Birkhoff's treatment of the expansion problem was insufficient and said so. Birkhoff supplied the omitted details in a paper which appeared a year later in the same journal (Rend. Circ. Mat. Palermo vol. 36 (1913) pp. 115-126) and J. D. acknowledged the suffciency of the supplementary argument in [8]. For further details in this matter, I refer to Marston Morse, George David Birkhoff and his 
mathematical work, Bull. Amer. Math. Soc. vol. 52 (1946), especially pp. 360-362. One observation should be made, however. Birkhoff restricts himself to a function $f(x)$ which is made up of a finite number of pieces, each real, continuous, and with continuous derivative, and proves that the expansion converges to $[f(x-0)+f(x+0)] / 2$ at all interior points and to certain linear combinations of $f(a+0)$ and $f(b-0)$ at the end points. Tamarkin, on the other hand, proves convergence to $[f(x-0)+f(x+0)] / 2$ at interior points if $f(x)$ is merely of bounded variation and he also shows that the expansion is equiconvergent and equi-summable $(C, 1)$ with the trigonometric Fourier series of $f(x)$ in $(a, b)$ when $f(x)$ is merely integrable. He does not say in what sense $f(x)$ is to be integrable, but even if he means Riemann integrable, his results contain those of Birkhoff for interior points as a very special case.

He continued these investigations in his dissertation [I] which is dated April, 1917. This is a practically self-contained, very detailed discussion of boundary value problems for linear differential systems. Starting with an outline of the theory of matrices, Lebesgue integration, and existence theorems, he proceeds to a discussion of the character of the solutions for large values of the complex parameter $\rho$, assuming the coefficient matrix to be analytic in $\rho$ outside a circle, except for a pole at infinity. The boundary conditions for the interval $(a, b)$ are of a very general nature, $U_{k}[y]=c_{k}, k=1,2, \cdots, n$. In the revised version [25] of 1927 his $U_{k}[y]$ are what in modern language would be called linear bounded functionals on the space $C^{(n-1)}[a, b]$, that is,

$$
U_{k}[y]=\sum_{m=0}^{n-1} \int_{a}^{b} y^{(m)}(t) d a_{k m}(t),
$$

but in [I] he restricts himself to the case in which each $a_{k m}(t)$ is the sum of a step function with a finite number of steps and an absolutely continuous function. The function of Green, the distribution of the characteristic values, and the expansion problem are studied in great detail. He proves the same type of equi-convergence and equi-summability theorems as in [6], but now explicitly for functions integrable in Lebesgue's sense. J. D.'s results in [I] represented the last word in the field for a number of years. These results, however, remained unknown outside of Russia practically until J. D. issued the English condensed and revised edition [25].

Papers [27] and [28] together with [43] mark different stages in the transition of J. D.'s interest from boundary value problems to the theory of integral equations. In [27] he shows that to a given integro- 
differential system you can construct a Green's function and the characteristic values of the problem are asymptotic to the characteristic values of a related differential system in such a manner that expansions in terms of fundamental functions of the two problems are equiconvergent and equi-summable. In [28] he and R. E. Langer show that certain integral equations are equivalent to integro-differential problems and hence soluble.

8. Integral equations $[20,21,28,33,42,44,45,64]$. The papers $[20,21]$ were written in Petrograd in 1924 and published in this country two years later. The first is concerned with the inversion of Laplace's integral, the second with a generalization of Volterra's equation. In [26] J. D. is concerned with an integral equation whose kernel $K(x, t, \lambda)$ is a holomorphic function of $\lambda$ in a domain $\Delta$ for almost all $x, t$. If the kernel is quadratically integrable for each $\lambda$ in $\Delta$, uniformly with respect to $\lambda$ in any fixed closed subset of $\Delta$, then either the resolvent kernel exists as a meromorphic function of $\lambda$ in $\Delta$ or the resolvent does not exist for any $\lambda$ in $\Delta$. The basic tool is the theory of infinite determinants. [28] was discussed above. In [42] J. D. gave a careful modern treatment of Abel's integral equation.

The remaining papers are chiefly concerned with the frequency of the characteristic values. T. Carleman, generalizing a result of I. Schur, had proved the inequality $\sum\left|\lambda_{n}\right|^{-2} \leqq \iint|K(x, t)|^{2} d x d t$ and had shown that the exponent of convergence could not be replaced by any smaller number than two even for continuous kernels. If, however, the kernel satisfies addition restrictions, it was known in some cases that better estimates hold. In $[33,45]$ we made a systematic investigation of the frequency problem under a large number of different assumptions of continuity, differentiability or analyticity. We replaced the integral equation by an equivalent system of linear equations for the Fourier coefficients of the solution in a suitable orthogonal system and discussed the equations with the aid of the theory of infinite determinants. We seem to have found this mode of attack independently of each other as well as the first crude estimates, but for the refined analysis the estimates given in [26] turned out to be very useful. J. D. also contributed the decisive artifice of modifying an optimum number of equations. This is probably our best joint paper, largely due to the ingenuity, knowledge, and technical skill displayed by J. D. In this investigation the kernel is supposed to be at least quadratically integrable. If merely the $p$ th power is integrable for some $p$ with $1 \leqq p<2$, the situation is strikingly different. In [44] we exhibited a symmetric kernel in $L_{p}$ whose spectrum is dense on the real axis as well as an unsymmetric kernel for which 
every $\lambda \neq 0$ is in the point spectrum. In [64] we showed that the transformation $g(x)=\int_{-\infty}^{\infty} K(x, t) f(t) d t$ is completely continuous (=compact) on $L_{p}$ to itself when $\int\left[\int|K(x, t)|^{p^{\prime}} d t\right]^{p / p^{\prime}} d x<\infty$, provided $p>1$. An example of $J$. von Neumann shows that this is no longer true for $p=1$. Both [44] and [64] contain a number of additional results concerning special integral equations.

9. Mathematical physics [17-19]. These three papers arose from his collaboration with Friedmann in 1922-1924. I regret that I cannot read [17] which is concerned with the propagation of discontinuities in a compressible fluid. The results of this paper seem to have an important bearing on the problem of the vertical motion of the atmosphere, a problem to which Friedmann had given a number of contributions. This connection is stated in [18] which also contains some numerical observations bearing out the theoretical conclusions. [19] is not available to me and does not seem to have been reviewed in either mathematical or physical abstract journals.

10. Approximations [III, 10,11, 13, 15, 16]. Of these [III] and [15] are not available to me. [10] is an elaboration of the method of W. Ritz written together with N. Krylov; the extensive corrections [11] are signed by J. D. alone. [13] deals with C. Störmer's method of approximate integration of ordinary differential equations; J. D. shows that the procedure is not merely suitable for numerical computations but is actually convergent. In [16] he and Krylov considered an interesting interpolation formula based upon the partial fraction expansions of the odd order derivatives of the cotangent; they establish convergence of the procedure at points of continuity and determine degree of approximation, and so on.

11. Abstract spaces $[49,57,68-71]$. These six notes are entirely unrelated. In [49] J. D. gave necessary and sufficient conditions in order that a subset of $L_{p}$ be compact. He generalized results of Kolmogoroff; other conditions were later given by M. Riesz. In [57] he and S. Saks studied operators of the form $\int_{a}^{b} f(t) d_{t} H(x, t)=U[f]$, where $H(x, t)$ is normalized and of bounded variation in $t$ for almost all $x$. They show that if $U[f]$ is essentially bounded in $x$ for each continuous $f(t)$, then the total variation of $H(x, t)$ is an essentially bounded function of $x$. [68] is written with M. H. Stone. The complex Euclidean spaces contain Hilbert space as a special case; the theorems refer to weak and strong forms of boundedness, completeness, and compactness and to conditions under which an operator or a matrix is bounded. In 1935-1936 J. D. lectured on polynomials of approxima- 
tion [C], and [69] is an outgrowth of this course. The problem is that of estimating the ratio of the $L_{p}$-norms of $f^{\prime}(x)$ and $f(x)$ when $f(x)$ is a polynomial of degree $n$. J. D. had found that the ratio is $O\left(n^{2}\right)$ and G. Szegö showed that this is the right order, but the best constant could not be found except when $p=2$ in which case the problem had already been solved by E. Schmidt. [70] is written with Nelson Dunford and its purpose is to establish theorems of the Fubini-Jessen type for abstract-valued functions. [71], written with A. Zygmund, is J. D.'s last publication. It contains a simplified proof of Thorin's extension of M. Riesz's convexity theorem from bilinear forms to entire functions of several complex variables.

\section{BIBLIOGRAPHY}

The subsequent list of J. D.'s books, research papers, and lecture notes is based upon a bibliography, mainly covering the period 19231931, which Professor R. C. Archibald has kindly placed at my disposal. This list has been checked as far as possible and extended to cover the forty years of J. D.'s scientific activities. I have not seen [II, III, IV, 3, 9, 15, 19], but the existence of these items appears to be well established. This also applies to the literary ownership of [III, IV]. Co-authors are listed under the number of the item in question; the initials used for this purpose can be read off from the list of collaborators.

\section{List of J. D. TAmarkin's Collaborators}

[AB] A. S. Besicovich

[JB] J. S. Besicovich

[ND] Nelson Dunford

[WF] W. K. Feller

[GF] G. M. Fichtenholz

[AF] A. A. Friedmann

[EH] Einar Hille

$\begin{array}{ll}\text { [HK] } & \text { E. L. Krall } \\ \text { [NK] } & \text { N. Krylov } \\ \text { [RL] } & \text { R. E. Langer } \\ \text { [AO] } & \text { A. C. Offord } \\ \text { [SS] } & \text { S. Saks } \\ \text { [JS] } & \text { J. A. Shohat } \\ \text { [LS] } & \text { L. L. Silverman }\end{array}$

Books
[VSm] V. I. Smirnov

[VSt] V. A. Steklov

[MS] M. H. Stone

[GS] Gabor Szegö

[CW] Ch. E. Wilder

[AZ] Antoni Zygmund

I. On some general problems in the theory of ordinary linear differential equations and on the expansion in series of arbitrary functions (In Russian), Petrograd, 1917, xiv $+308 \mathrm{pp}$.

II. A course in higher mathematics for engineers and physicists (In Russian),

[VSm] Petrograd, vol. 1, 1924, 420 pp., vol. 2, 1925, 408 pp.

III. A course in mathematics for engineers (In Russian), Leningrad, 1926, [GF] $300 \mathrm{pp}$.

IV. Approximate computations (In Russian), Leningrad, 1925, 150 pp. [JB, AF]

V. The problem of moments. Mathematical Surveys, vol. 1, New York, 1943, [JS] $\quad$ xiv $+140 \mathrm{pp}$. 


\section{Research Papers}

1. Sur les congruences du second degre et les nombres de Bernoulli, Math. Ann. [AF] vol. 62 (1906) pp. 409-412.

2. Quelques formules concernant la theorie de la fonction $[x]$ et les nombres de

[AF] Bernoulli, Journal für Mathematik vol. 135 (1909) pp. 146-156.

3. Application de la méthode des fonctions fondamentales al l'étude de l'équation differentielle des verges vibrantes élastiques, Communications de la Société mathématique de Kharkow (2) vol. 12 (1910) pp. 19-46.

4. Problème des vibrations transversales d'une verge élastique homogène, Rend.

[VSt] Circ. Mat. Palermo vol. 31 (1911) pp. 341-362.

5. Sur le problème des vibrations transversales d'une verge elastique hêtérogène, C. R. Acad. Sci. Paris vol. 154 (1912) pp. 269-271.

6. Sur quelques points de la théorie des équations différentielles linéaires ordinaires et sur la gênéralisation de la série de Fourier, Rend. Circ. Mat. Palermo vol. 34 (1912) pp. 345-382.

7. Problème du developpement d'une fonction en série de Sturm-Liouville, C. R. Acad. Sci. Paris vol. 156 (1913) pp. 1589-1591.

8. Sur un problème de la thêorie des équations différentielles linéaires ordinaires, Rend. Circ. Mat. Palermo vol. 37 (1914) pp. 376-378.

9. On a theorem in the integral calculus (In Russian), Annales de l'Institute Electrotechnique, Petrograd vol. 13 (1916) pp. 19-22.

10. Sur la méthode de W. Ritz pour la solution approchée des problèmes de la phy[NK] sique mathématique, Bulletin de l'Académie des Sciences de Russie, Petrograd (6) vol. 12 (1918) pp. 69-88.

11. Complément à l'article "Sur la méthode de W. Ritz pour la solution approchée des problèmes de la physique mathématique," Bulletin de l'Académie des Sciences de Russie, Petrograd (6) vol. 15 (1921) pp. 327-332.

12. Sur le thêorème d'unicité des solutions des équations différentielles ordinaires, Math. Zeit. vol. 16 (1923) pp. 207-213.

13. Sur la méthode de C. Störmer pour l'intégration approchée des équations diffêrentielles ordinaires, Math. Zeit. vol. 16 (1923) pp. 214-219.

14. Über die asymptotischen Ausdrücke für die Integrale eines Systems linearer [AB] Differentialgleichungen, die von einem Parameter abhängen, Math. Zeit. vol. 21 (1924) pp. 119-125.

15. Sur l'application de la thêorie des quadratures mécaniques gênéralisées d [NK] l'évaluation par approximations succesives de la solution de l'équation intégrale, Bulletin de l'Académie des Sciences de l'Oukraine, Kiev vol. 1 (1923) pp. 19-21.

16. Sur une formule d'interpolation, Proceedings of the International Mathe[NK] matical Congress, Toronto, 1924, vol. 1, Toronto, 1928, pp. 641-650.

17. On the propagation of discontinuities in a compressible fuid (In Russian),

[AF] Journal de la Societé Physico-Chimique de Russie, Moscou vol. 56 (1924) pp. 40-58.

18. Über eine Methode der Bestimmung der vertikalen Windgeschwindigkeit, [AF] Meteorologische Zeitschrift vol. 41 (1924) pp. 90-91.

19. On possible configurations of electrons in the Rutherford atom (In Russian), [AF] GosudarstvennyI Opticheskil Institut, Trudy vol. 3 (1924).

20. On Laplace's integral equation. Trans. Amer. Math. Soc. vol. 28 (1926) pp. 417-425. 
21. On Volterra's integro-functional equation, Trans. Amer. Math. Soc. vol. 28 (1926) pp. 426-431.

22. Note on the second law of the mean for integrals, Bull. Amer. Math. Soc. [CW] vol. 32 (1926) pp. 151-152.

23. A notion of uniform integrability, Bull. Amer. Math. Soc. vol. 32 (1926) pp. [RL] 335-337.

24. A new proof of Parseval's identity for trigonometric functions, Ann. of Math. (2) vol. 27 (1926) pp. 541-547.

25. Some general problems of the theory of ordinary linear differential equations and expansion of an arbitrary function in series of fundamental functions, Math. Zeit. vol. 27 (1927) pp. 1-54.

26. On Fredholm's integral equations, whose kernels are analytic in a parameter, Ann. of Math. (2) vol. 28 (1927) pp. 127-152.

27. The notion of the Green's function in the theory of integro-differential equations, Trans. Amer. Math. Soc. vol. 29 (1927) pp. 755-800.

28. On integral equations with discontinuous kernels, Trans. Amer. Math. Soc. [RL] vol. 30 (1928) pp. 453-471.

29. The zeros of certain integral functions, J. London Math. Soc. vol. 2 (1927) pp. 66-69.

30. Some geometric illustrations for the elementary course in differential equations, Amer. Math. Monthly vol. 35 (1928) pp. 27-29, 306.

31. Solution of a problem proposed by L. L. Silverman and J. Tamarkin, Amer. Math. Monthly vol. 35 (1928) pp. 497-500.

32. On the generalization of Abel's theorem for certain definitions of summability, [LS] Math. Zeit. vol. 29 (1928) pp. 161-170.

33. On the characteristic values of linear integral equations, Proc. Nat. Acad. [EH] Sci. U.S.A. vol. 14 (1928) pp. 911-914.

34-38. On the summability of Fourier series. Five notes. Proc. Nat. Acad. Sci.

[EH] U.S.A. vol. 14 (1928) pp. 915-918, vol. 15 (1929) pp. 41-42, vol. 16 (1930) pp. 594-598, vol. 17 (1931) pp. 376-380, vol. 20 (1934) pp. 369-372.

39. Remarks on a known example of monotone continuous function, Amer. Math. [EH] Monthly vol. 36 (1929) pp. 255-264.

40. Sur une rélation entre des resultats de MM. Minetti et Valiron, C. R. Acad. [EH] Sci. Paris vol. 188 (1929) p. 1142.

41. A lemma in the theory of linear differential systems, Bull. Amer. Math. Soc. vol. 36 (1930) pp. 99-102.

42. On integrable solutions of Abel's integral equation, Ann. of Math. (2) vol. 31 (1930) pp. 219-229.

43. The notion of the Green's function in the theory of integro-differential equations. II, Trans. Amer. Math. Soc. vol. 32 (1930) pp. 860-868.

44. On the theory of linear integral equations. I, Ann. of Math. (2) vol. 31 (1930) [EH] pp. 479-528.

45. On the characteristic values of linear integral equations, Acta Math. vol. 57 [EH] (1931) pp. 1-76.

46. Remarks on a paper of Dr. Tautz, Acta Math. vol. 57 (1931) pp. 459-463.

[MS]

47. A well known theorem of integral calculus, Amer. Math. Monthly vol. 38 [HK] (1931) pp. 324-326.

48. On a theorem of S. Bernstein-Widder, Trans. Amer. Math. Soc. vol. 33 (1931) pp. 893-896. 
49. On the compactness of the space $L_{p}$, Bull. Amer. Math. Soc. vol. 38 (1932) pp. 79-84.

50. On the summability of Fourier series, Trans. Amer. Math. Soc. vol. 34 [EH] (1932) pp. 757-783.

51. Remarks on the theory of conjugate functions, Proc. London Math. Soc. (2) vol. 34 (1932) pp. 379-391.

52. The summation of Fourier series by Hausdorff means, Verhandlungen des

[EH] Internationalen Mathematiker-Kongresses, Zürich 1932, vol. II, pp. 131132.

53. On summability of Fourier series, Verhandlungen des Internationalen

[EH] Mathematiker-Kongresses, Zürich 1932, vol. II, pp. 133-134.

54. On the summability of Fourier series. II, Ann. of Math. (2) vol. 34 (1933)

[EH] pp. 329-348, 602-605.

55. On the summability of Fourier series. III, Math. Ann. vol. 108 (1933) pp.

[EH] 525-577.

56. Questions of relative inclusion in the domain of Hausdorff means, Proc. Nat.

[EH] Acad. Sci. U.S.A. vol. 19 (1933) pp. 573-577.

57. On a theorem of Saks-Steinhaus, Ann. of Math. (2) vol. 34 (1933) pp. 595[SS] 601 .

58. On a theorem of Paley and Wiener, Ann. of Math. (2) vol. 34 (1933) pp.

[EH] 606-614.

59. On moment functions, Proc. Nat. Acad. Sci. vol. 19 (1933) pp. 902-908.

[EH]

60. On the theory of Laplace integrals, Proc. Nat. Acad. Sci. U.S.A. vol. 19 [EH] (1933) pp. 908-912.

61. On the theory of Fourier transforms, Bull. Amer. Math. Soc. vol. 39 (1933)

[EH] pp. 768-774.

62. A remark on Fourier transforms and functions analytic in a half-plane,

[EH] Compositio Math. vol. 1 (1934) pp. 98-102.

63. On the theory of Laplace integrals. II, Proc. Nat. Acad. Sci. U.S.A. vol. 20 [EH] (1934) pp. 140-144.

64 On the theory of linear integral equations. II, Ann. of Math. (2) vol. 35 (1934)

[EH] pp. 445-455.

65. On the notion of regularity of methods of summation of infinite series, Bull. Amer. Math. Soc. vol. 41 (1935) pp. 241-243.

66. Some observations on the theory of Fourier transforms, Bull. Amer. Math.

[EH, AO] Soc. vol. 41 (1935) pp. 427-436.

67. On the absolute integrability of Fourier transforms, Fund. Math. vol. 25 [EH] (1935) pp. 329-352.

68. Elementary proofs of some known theorems of the theory of complex Euclidean [MS] spaces, Duke Math. J. vol. 3 (1937) pp. 294-302.

69. On some generalizations of a theorem of $A$. Markoff, Duke Math. J. vol. 3 [EH, GS] (1937) pp. 729-739.

70. A principle of Jessen and general Fubini theorems, Duke Math. J. vol. 8 [ND] (1941) pp. 743-749.

71. Proof of a theorem of Thorin, Bull. Amer. Math. Soc. vol. 50 (1944) pp. 279[AZ] 282.

\section{Mimeographed Lecture Notes}

A. Integral equations, Lectures delivered at Brown University during 19311932, Providence, 1932, iii +368 pp. 
B. Theory of Fourier series, Lectures delivered at Brown University during 1932-1933, Providence, 1933, vi +319 pp.

C. On the theory of polynomials of approximation, Lectures delivered at Brown University during 1935-1936, Providence, 1936, 186 pp.

D. Theory of abstract spaces, Lectures delivered at Brown University during 1936-1937, Providence, 1937, 215 pp.

E. Partial differential equations, Brown University, Summer Session for Ad[WF] vanced Instruction and Research in Mechanics, 1941, x+268 pp. [Chapters I-III by J.D.T., chapters IV-VII by W.F.] 